\title{
SISTEM PRESENSI MAHASISWA MENGGUNAKAN QR CODE DENGAN FITUR GEOLOCATION DAN ENKRIPSI AES
}

\author{
Mochamad Alfan Rosid ${ }^{1}$, Sumarno ${ }^{2}$ \\ ${ }^{1,2}$ Program Studi Informatika, Fakultas Sains dan Teknologi \\ Universitas Muhammadiyah Sidoarjo \\ Jalan Mojopahit 666 B Sidoarjo Jawa Timur Indonesia \\ Co Responden Email : alfanrosid@umsida.ac.id
}

Article history
Received Jan 28, 2021
Revised June 27, 2021
Accepted June 29, 2021
Available online June 30, 2021
Keywords
Presences,
QR Code,
encryption,
AES,
Geolocation

Riwayat

Diterima 28 Janiari 2021

Revisi 27 Juni 2021

Disetujui 29 Juni 2021

Terbit 30 Juni 2021

Kata Kunci

Presensi,

QR Code

Enkripsi,

AES,

Geolocation

\begin{abstract}
This research aims to create a student presence system using the $Q R$ Code (Quick Response Code) with AES encryption, when the learning process will begin, lecturers display QR Code for further scans by students through their smartphones that have been installed academic information system, data presences will be automatically stored in the database, the data can be known directly by lecturers and students. Data security uses AES encryption methods and in order to ensure that students are actually present then this research also implements Geolocation, if Geolocation on the student's smartphone is not the same as that in the presences system then the student is not able to perform the presences. From the results of the research, the system can run well, with the existence of this system can simplify the process of presences and increase efficiency because no more presences printed on paper.
\end{abstract}

\begin{abstract}
Abstrak
Penelitian ini bertujuan untuk membuat sebuah sistem presensi mahasiswa menggunakan QR Code (Quick Response Code) dengan enkripsi AES, pada saat proses pembelajaran akan dimulai, dosen menampilkan QR Code untuk selanjutnya di scan oleh mahasiswa melalui smartphone mereka yang telah terinstal sistem informasi akademik, data presensi akan secara otomatis tersimpan pada database, data tersebut dapat diketahui secara langsung oleh dosen dan mahasiswa. Pengamanan data menggunakan metode enkripsi AES dan agar dapat memastikan bahwa mahasiswa benar-benar hadir maka penelitian ini juga menerapkan Geolocation, apabila Geolocation pada smartphone mahasiswa tidak sama dengan yang ada di sistem presensi maka mahasiswa tersebut tidak dapat melakukan presensi. Dari hasil penelitian, sistem dapat berjalan dengan baik, dengan adanya sistem ini dapat mempermudah proses presensi dan meningkatkan efisiensi karena tidak diperlukan lagi presensi yang dicetak pada kertas.
\end{abstract}

\section{PENDAHULUAN}

Pada era evolusi industri 4.0, diperlukan inovasi untuk menggantikan caracara konvensional (Utami et al., 2019)yang selama ini masih dilakukan, salah satu inovasi yang dapat diterapkan pada dunia industri, mulai dari industry hulu sampai hilir tidak menutup kemungkinan juga menyasar pada dunia industry pendidikan seperti perguruan tinggi. Universitas yang memiliki jumlah mahasiswa ribuan tentunya sangat membutuhkan perangkat yang terintegrasi. Salah satu universitas yang masih menggunakan sistem informasi presensi adalah Universitas Muhammadiyah Sidoarjo. Sistem presensi yang dimiliki masih terdapat kelemahan diantaranya presensi masih dilakukan oleh dosen pengampu pada sistem presensi setelah mahasiswa mengisi form presensi manual, hal ini tentunya kurang efisien dan dosen bisa saja lupa untuk memasukkan bahkan ada kesalahan input ke sistem. Selain itu mahasiswa juga tidak bisa mengecek secara 
langsung data presensi mereka karena harus menunggu dosen pengampu memasukkan ke sistem.

Ahmad Rifai dkk (2017) melakukan penelitian yang menghasilkan sistem presensi mahasiswa berbasis online, pada sistem yang dihasilkan menggunakan teknologi web dimana dosen akan memasukkan data presensi mahasiswa pada sistem tersebut, pada sistem yang dihasilkan masih memiliki kekurangan yaitu presensi harus diinputkan oleh dosen sendiri (Rifai, 2017), (Nasution, 2018; Tan, Kartawihardja, \& Christian, 2017)menghasilkan penelitian berupa sistem presensi berbasis RFID, mahasiswa cukup melakukan scan KTM (Kartu Tanda Mahasiswa) yang berisi RFID untuk melakukan presensi, namun menurut penulis, sistem ini masih memiliki kekurangan yaitu, mahasiswa dapat menitipkan KTM mereka ke teman yang masuk kuliah, sehingga data presensi yang masuk bisa jadi tidak valid.

Sedangkan (Hermanto et al., 2019; Supendi, Supriadi, \& Isto, 2019) melakukan penelitian yang menghasilkan sistem presensi mahasiswa dengan memanfaatkan teknologi QR-Code berbasis mobile, pada penelitian ini mahasiswa cukup melakukan scan QR-Code dengan perangkat mobile mereka, dengan demikian Aplikasi absensi ini dapat mengurangi kecurangan mahasiswa dalam pengisian absen saat perkuliahan berlangsung di dalam kelas, proses rekapitulasi absen dilakukan dengan lebih mudah dan efisien oleh dosen pengampu serta mahasiswa dapat dengan lebih mudah melihat dan mengetahui jumlah pertemuan yang telah diikuti (Supendi et al., 2019).

Antonius Erick Handoyo dkk(2018) meneliti penggunaan enkripsi RSA untuk menyembunyikan pesan pada citra digital dengan kombinasi metode LSB, pada penelitian ini dapat meningkatkan keamanan karena kunci kombinasi $\mathrm{p}$ dan $\mathrm{q}$ dapat bervariasi(Handoyo et al., 2018). Dengan variasi yang semakin banyak maka enkripsi RSA dapat lebih aman. Metode ini juga berhasil digabungkan dengan steganografi LSB.

(Saefudin \& Syamsudin, 2017) meneliti penggunaan enkrpsi Advanced Encryption Standard(AES) pada pesan teks berbasis android, penelitian ini bertujuan untuk mengamankan pesan teks sehingga pertukaran data menjadi lebih aman, enkripsi AES dipilih karena dianggap paling kuat diantara enkripsi lainnya. Dengan enkripsi AES pesan teks yang telah di enkripsi dapat dikembalikan ke bentuk semula dengan fungsi dekripsi.

Berdasarkan latar belakan diatas, penelitian ini bermaksud untuk membangun sistem informasi presensi mahasiswa menggunakan QR-Code dan enkripsi AES untuk mengamankan data yang ada didalam kode QR, enkripsi AES saat ini dianggap paling kuat (Dian \& Arifudin, 2019; Harper, 2018)selain enkripsi AES, enkripsi RSA merupakan algoritma kriptografi asimetris yang paling sering digunakan pada saat ini dikarenakan kehandalannya(Manurung, Sirait, Panggabean, \& Komputer, 2018), namun penelitian ini lebih memilih AES yang lebih cepat dibanding RSA, kemudian penelitian ini juga menambahkan fitur Geolocation untuk memastikan bahwa mahasiswa benar-benar melakukan scan QR-Code di lokasi yang sama dengan dosen pengampu, sehingga data presensi lebih akurat dan aman. QR code sendiri adalah matrik dua dimensi (barcode) dengan pembacaan yang cepat dan kapasitas penyimpanan karakter yang lebih besar(Supendi et al., 2019; Tampubolon, Isnanto, \& Sinuraya, 2015). Sistem juga dibangun menggunakan framework twitter bootstrap yang menjadikan tampilan menjadi lebih simpel, ringan dan responsive (Rosid \& Jakaria, 2016). Dengan kombinasi QR-Code dan enkripsi AES serta geolocation diharapkan dapat menghasilkan sistem presensi yang lebih efisien dan aman.

\section{METODE PENELITIAN}

Penelitian ini melalui beberapa tahapan diantaranya analisa kebutuhan sistem, pada tahap ini dikumpulkan kebutuhan pengguna dan dilakukan penentuan konsep untuk menjawab kebutuhan pengguna tersebut, setelah itu dilakukan tahap desain/perancangan sistem, setelah tahapan desain selesai langkah selanjutya adalah mengimplementasikan ke dalam kode program dan yang terakhir adalah tahap pengujian(Sari et al., 2019).

\section{Perancangan dan Pembuatan Sistem}

Perancangan sistem merupakan bagian yang penting dalam membuat suatu sistem ataupun aplikasi, perancangan sistem ini dimaksudkan untuk memberikan gambaran umum tentang aplikasi yang akan dibuat. 


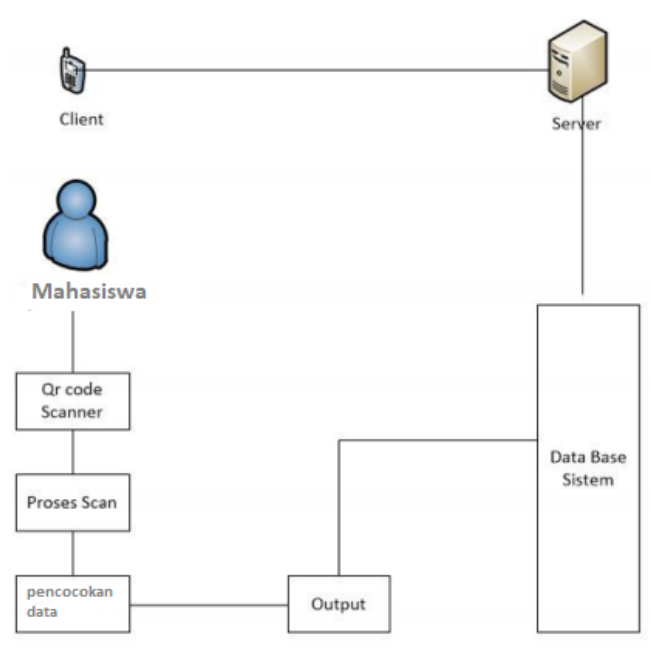

Gambar 1 Arsitektur Sistem Presensi Mahasiswa

Pada gambar 1 dapat dilihat bahwa sistem yang akan dibuat memiliki alur kerja yaitu mahasiswa akan melakukan scan qr code, setelah itu sistem akan melakukan pencocokan data yang kemudian akan menampilkan output sesuai dengan database sistem.

\section{Flowchart Sistem}

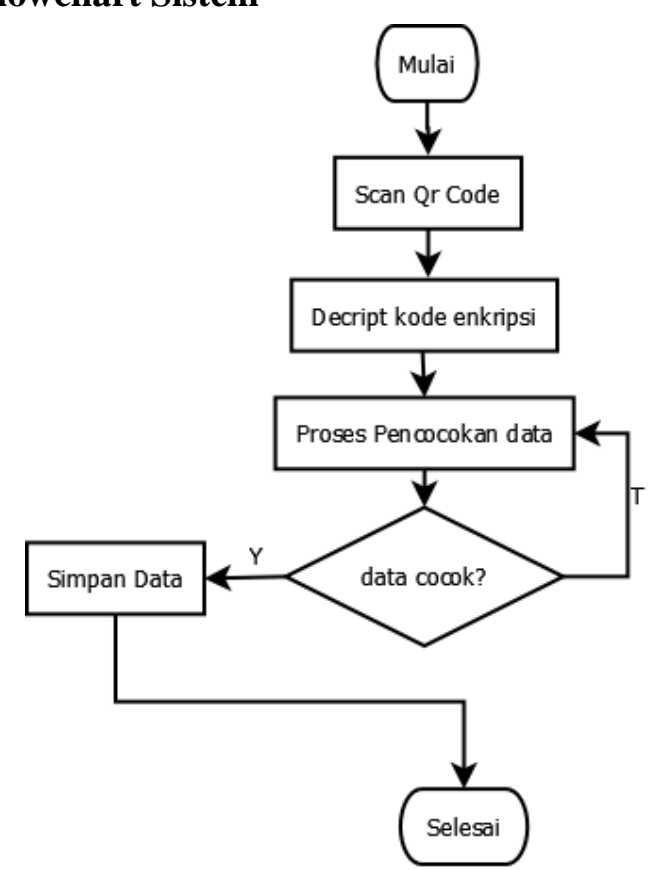

Gambar 2 Flowchart Sistem

Pada gambar 2, sistem dimulai dari mahasiswa melakukan scan Qr Code, setelah itu sistem melakukan dekripsi data untuk mengetahui isi dari Qr Code, setelah data berhasil di dekripsi selanjutnya sistem melakukan proses pencocokan data, jika data cocok maka sistem menyimpan data presensi mahasiswa lalu selesai, jika tidak cocok maka kembali ke proses pencocokan data.

\section{Use Case Diagram}

Perancangan use case diagram dipergunakan untuk melakukan pemodelan terhadap sistem yang akan dibangun (Rizky \& Ramdhani, 2019), sehingga dapat dipahami alur informasi dan akses datanya. Pada gambar 3 adalah use case diagram sistem presensi QR Code.

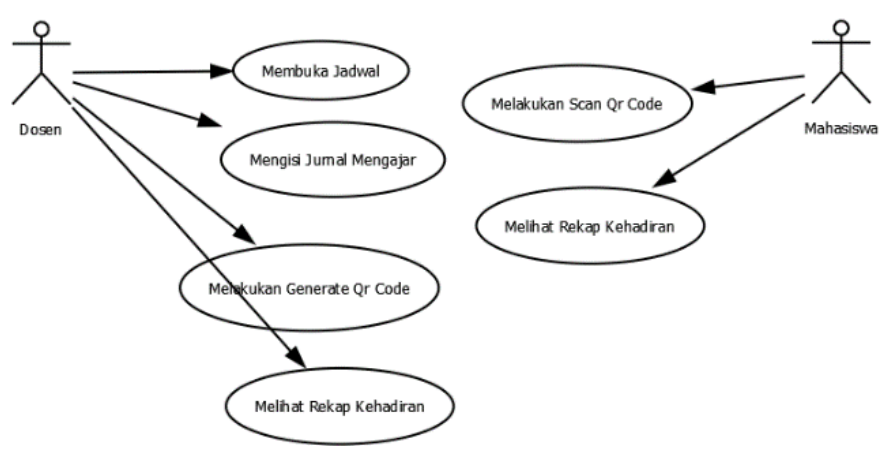

Gambar 3 Use Case Diagram

\section{Rancangan Antar Muka}

1. Rancangan Halaman Presensi dan Jurnal Mengajar

Pada halaman ini ada penambahan fitur baru dari halaman presensi dan jurnal mengajar di sistem lama. Penambahannya berupa menu presensi Qr Code yang di wakili oleh icon menu QR Code seperti yang ditunjukkan oleh gambar 4. ketika icon tersebut di klik maka akan masuk ke halaman pengisian jurnal mengajar dosen

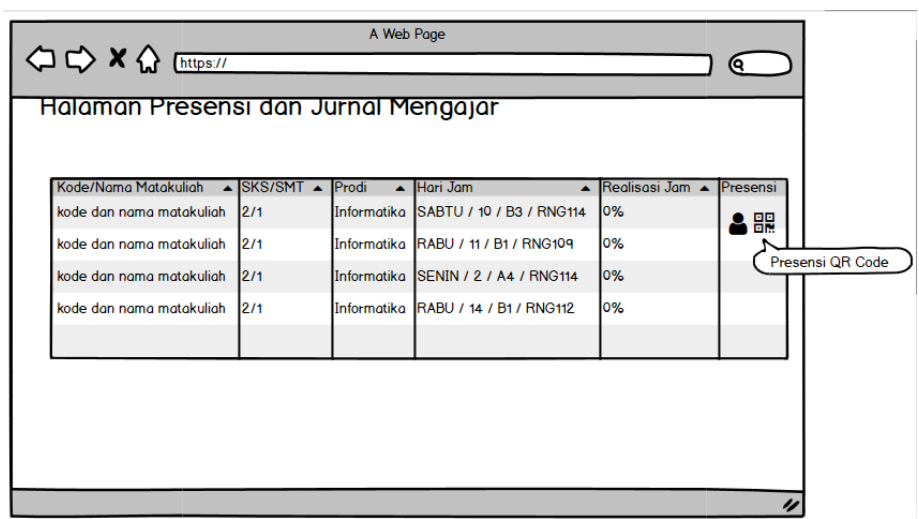

Gambar 4 Halaman Presensi dan Jurnal Mengajar 
2. Halaman Jurnal Mengajar

Pada halaman yang ditunjukkan oleh gambar 5, terdapat tombol untuk menampilkan QR Code presensi mahasiswa, tombol ini ditekan setelah dosen pengampu mengisi jurnal mengajar. Ketika tombol tampilkan QR Code ditekan maka akan di tampilkan halaman QR Code untuk selanjutnya di scan oleh mahasiswa.

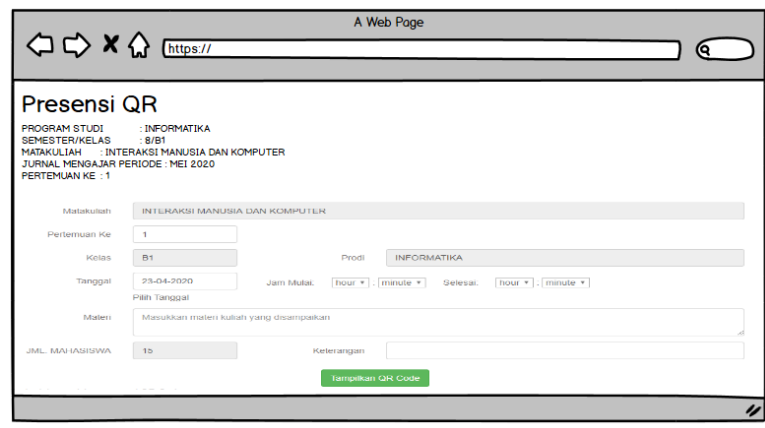

Gambar 5. Halaman Jurnal Mengajar

3. Rancangan Halaman QR Code Pada halaman ini ditampilkan QR Code yang harus di scan oleh mahasiswa untuk melakukan presensi, halaman ini juga di tampilkan data mahasiswa yang telah melakukan scanning QR Code. Adapun rancangan antarmukanya dapat dilihat pada gambar 6 .

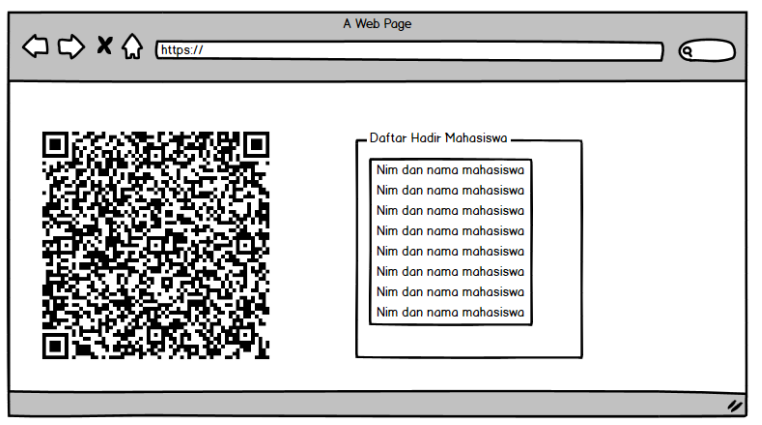

Gambar 6. Halaman QR Code

4. Rancangan halaman scan QR mahasiswa

Pada halaman ini digunakan mahasiswa untuk melakukan scanning qr code yang ditampilkan, Qr Code yang di tampilkan mengandung data yang akan di enkripsi dengan AES.

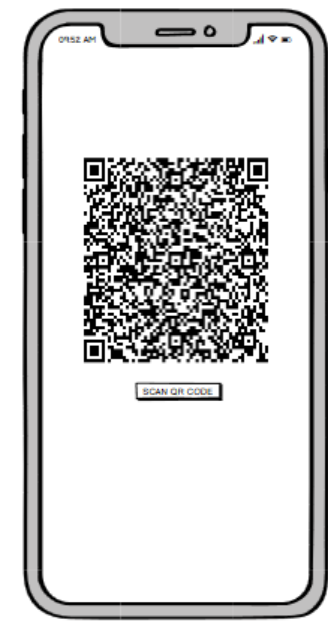

Gambar 7. Rancangan Halaman Scan QR

\section{HASIL DAN PEMBAHASAN}

\section{Antarmuka Sistem}

Penelitian ini menghasilkan 2 antarmuka sistem presensi mahasiswa yaitu antarmuka untuk dosen dan antarmuka untuk mahasiswa.

1. Halaman presensi dan jurnal mengajar dosen

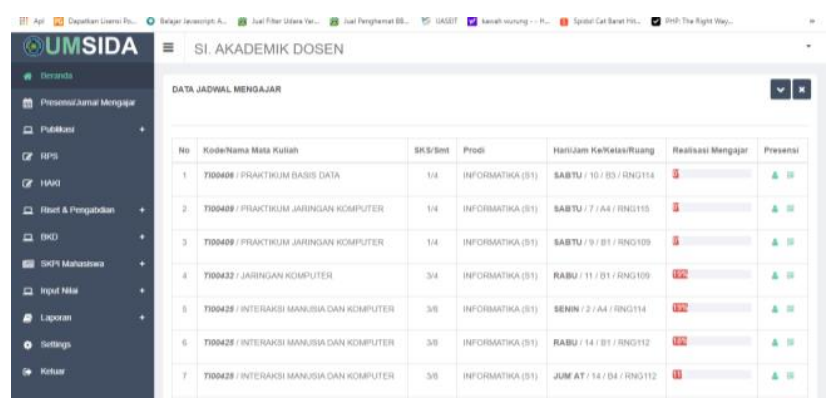

Gambar 8. Halaman presensi dan jurnal mengajar dosen

Pada halaman ini ada penambahan fitur baru dari halaman presensi dan jurnal mengajar di sistem lama. Penambahannya berupa menu presensi Qr Code yang di wakili oleh icon menu QR Code seperti yang ditunjukkan oleh gambar 8. ketika icon tersebut di klik maka akan masuk ke halaman pengisian jurnal mengajar dosen. 
2. Halaman Jurnal Mengajar

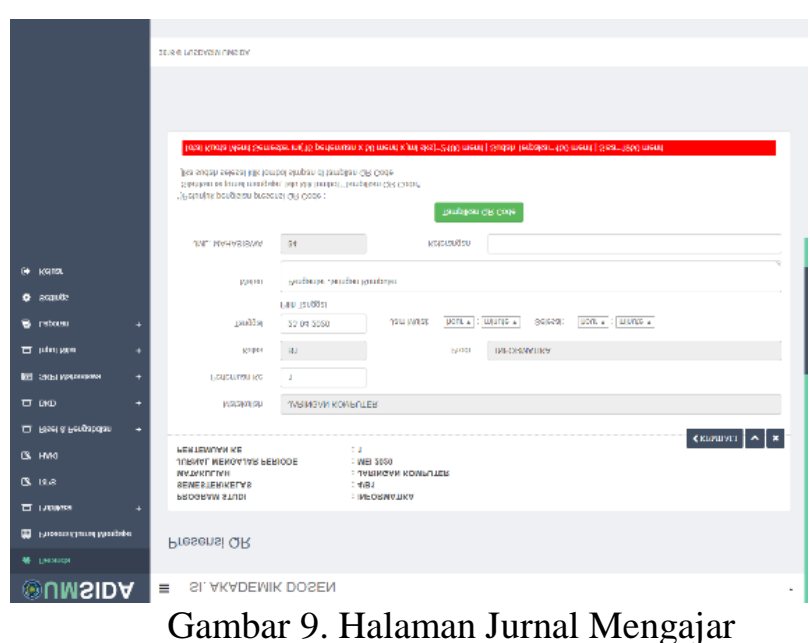

Pada halaman yang ditunjukkan oleh gambar 9 adalah halaman untuk menginput jurnal mengajar dosen, terdapat tombol untuk menampilkan QR Code presensi mahasiswa, tombol ini ditekan setelah dosen pengampu mengisi jurnal mengajar. Ketika tombol tampilkan QR Code ditekan maka akan di tampilkan halaman QR Code untuk selanjutnya di scan oleh mahasiswa.

3. Halaman QR Code

Pada halaman ini ditampilkan QR Code yang harus di scan oleh mahasiswa untuk melakukan presensi, halaman ini juga di tampilkan data mahasiswa yang telah melakukan scanning QR Code. Adapun rancangan antarmukanya dapat dilihat pada gambar 10 .

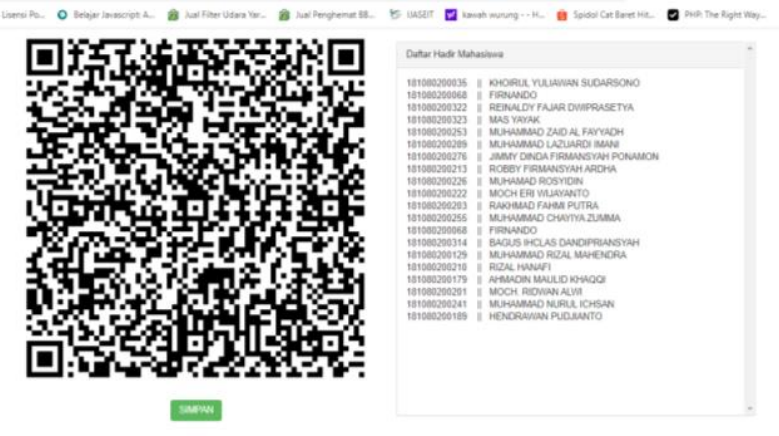

Gambar 10. Halaman QR Code

Berikut ini adalah potongan source code yang dipakai untuk menampilkan halaman pada gambar 10 .

<script>

function getLocation() \{

if (navigator.geolocation) \{

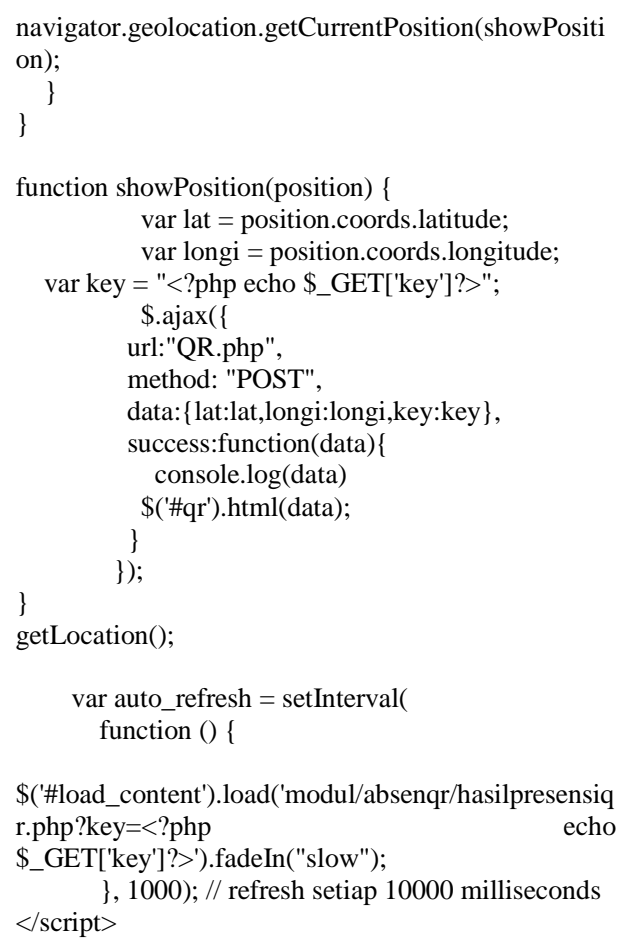

\$('\#load_content').load('modul/absenqr/hasilpresensiq r.php?key=<?php

\$_GET['key']?>').fadeIn("slow"); $</$ script $>$

\}, 1000); // refresh setiap 10000 milliseconds

Script yang digunakan menggunakan bahasa pemrograman javascript untuk memanggil file QR.php yang bertugas menampilkan QR Code dan memanggil file hasilpresensiqr.php untuk menampilkan data mahasiswa yang telah melakukan scan QR

4. Halaman scan QR mahasiswa

Pada halaman ini digunakan mahasiswa untuk melakukan scanning qr code yang ditampilkan, ketika QR Code terscan, maka sistem memeriksa terlebih dahulu, apakah mahasiswa tersebut terdaftar di matakuliah yang di ampu dosen kemudian apakah lokasi mahasiswa ada di kelas dengan menggunakan rumus jarak longitude dan latitude serta memeriksa apakah mac address atau alamat fisik dari handphone sudah di gunakan untuk scan atau belum untuk menghindari titip presensi dari mahasiswa yang tidak masuk. Tampilan halaman ini di tunjukkan oleh ganbar 11. 


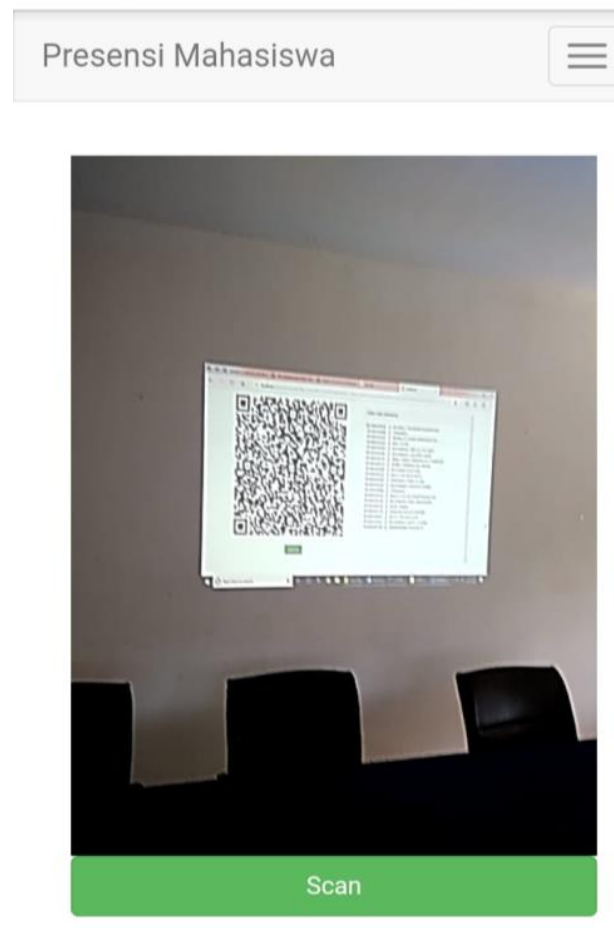

Gambar 11. halaman scan QR Code oleh mahasiswa

5. Halaman scan QR Sukses

Pada halaman ini menampilkan hasil scan di handphone mahasiswa, apakah berhasil melakukan presensi atau tidak berdasarkan kriteria yang telah disebutkan di poin 4. Adapun tampilan halaman ini dapat dilihat di gambar 12.

\title{
PRESENSI SUKSES
}

\author{
MAC : 0c-98-38-5a-db-4d \\ longitude: 112.7107377 \\ latitude: -7.4915441
}

Gambar 12. Tampilan Scan Sukses

\section{Hasil Pengujian}

tahap pengujian terhadap program yang dibuat menggunakan blackbox testing, pengujian difokuskan pada proses masukan dan keluaran. Tabel 1 berikut merupakan hasil pengujian black box pada halaman menu scan QR Code.

Tabel 1. Hasil pengujian dengan metode black box

\begin{tabular}{|c|c|c|c|c|c|}
\hline No & $\begin{array}{l}\text { Skenario } \\
\text { Pengujian }\end{array}$ & Test Case & $\begin{array}{l}\text { Hasil yang } \\
\text { diharapkan }\end{array}$ & $\begin{array}{l}\text { Hasil } \\
\text { pengujian }\end{array}$ & Kesimpulan \\
\hline 1 & $\begin{array}{l}\text { Halaman scan } \\
\text { QR } \\
\text { menampilkan } \\
\text { fitur kamera }\end{array}$ & $\begin{array}{l}\text { Diberikan } \\
\text { input gambar } \\
\text { QR Code }\end{array}$ & $\begin{array}{l}\text { Dapat } \\
\text { melakukan } \\
\text { scan terhadap } \\
\text { QR Code }\end{array}$ & $\begin{array}{l}\text { Sesuai } \\
\text { Harapan }\end{array}$ & Valid \\
\hline 2 & $\begin{array}{l}\text { Halaman } \\
\text { Proses } \\
\text { Presensi }\end{array}$ & \begin{tabular}{l}
\multicolumn{2}{l}{ Diberikan } \\
input lokasi \\
dan mac \\
address client
\end{tabular} & $\begin{array}{l}\text { Dapat } \\
\text { menampilkan } \\
\text { posisi } \\
\text { longitude dan } \\
\text { latitude serta } \\
\text { mac address } \\
\text { dari client }\end{array}$ & $\begin{array}{l}\text { Sesuai } \\
\text { Harapan }\end{array}$ & Valid \\
\hline 3 & $\begin{array}{l}\text { Halaman } \\
\text { tampil Qr } \\
\text { Code dan data } \\
\text { presensi }\end{array}$ & $\begin{array}{l}\text { Diberikan } \\
\text { input data } \\
\text { presensi }\end{array}$ & $\begin{array}{l}\text { Dapat } \\
\text { menampilkan } \\
\text { QR Code dan } \\
\text { Data Presensi }\end{array}$ & $\begin{array}{l}\text { Sesuai } \\
\text { Harapan }\end{array}$ & Valid \\
\hline
\end{tabular}




\section{PENUTUP}

Dari hasil penelitian ini dapat disimpulkan bahwa sistem presensi dapat berjalan dengan baik untuk melakukan scan QR Code dan memproses data presensi, sistem dapat memfilter lokasi mahasiswa sehingga hanya mahasiswa yang berada di lokasi saja yang dapat diterima, data yang ada di dalam QR Code di enkripsi dengan metode AES. Dengan demikian dengan adanya sistem ini dapat mempermudah proses presensi dan meningkatkan efisiensi karena tidak diperlukan lagi presensi yang dicetak pada kertas

\section{Ucapan Terimakasih}

Dengan ini kami ucapkan terima kasih kepada Universitas Muhammadiyah Sidoarjo yang telah membiayai dan mendukung publikasi penelitian ini.

\section{DAFTAR PUSTAKA}

Dian, H., \& Arifudin, R. (2019). Security Login System on Mobile Application with Implementation of Advanced Encryption Standard ( AES ) using 3 Keys Variation 128-bit, 192-bit , and 256-bit, 6(1), 34-44.

Handoyo, A. E., Ignatius, D. R., Setiadi, M., Rachmawanto, E. H., Sari, C. A., Setiadi, D. R. I. M., ... Susanto, A. (2018). Teknik Penyembunyian dan Enkripsi Pesan pada Citra Digital dengan Kombinasi Metode LSB dan RSA, 6(November 2017), 37-43. https://doi.org/10.14710/jtsiskom.6.1.2018. $37-43$

Harper, R. (2018). AES Proposal: Rijndael. In Unsettling the West (pp. ix-xii). https://doi.org/10.9783/9780812294491001

Hermanto, N., Studi, P., Informatika, T., Studi, P., Informati, S., Rahmat, N., ... Informatika, T. (2019). Aplikasi sistem presensi mahasiswa berbasis android, 10(1), 107-116.

Manurung, J., Sirait, K., Panggabean, J. F., \& Komputer, D. (2018). PENERAPAN ALGORITMA RSA UNTUK PENGAMANAN FILE, 2(2), 112-116.

Nasution, S. (2018). PRESENSI ONLINE MENGGUNAKAN RFID PADA KARTU MAHASISWA. Photosynthetica, 2(1), 113. Retrieved from
https://journal.ipm2kpe.or.id/index.php/IN TECOM/article/view/142

Rifai, A. (2017). Perancangan Sistem Presensi Mahasiswa Berbasis Online, 3(1), 191-193.

Rizky, A. A., \& Ramdhani, I. (2019).

Perancangan Sistem Informasi Perekrutan

Karyawan Berbasis Web Menggunakan

PHP dan MySQL DI PT. Ria Indah

Mandiri. Jurnal Manajemen Informatika

(JAMIKA), 9(1), 49-57.

https://doi.org/10.34010/jamika.v9i1.1651

Rosid, M. A., \& Jakaria, R. B. (2016).

Implementasi Framework Twitter

Bootstrap Dalam Perancangan Aplikasi

Penerimaan Mahasiswa Baru Berbasis

Web. Kinetik, 1(3), 129.

https://doi.org/10.22219/kinetik.v1i3.121

Saefudin, S., \& Syamsudin, S. (2017). Aplikasi

Enkripsi Pesan Teks Dengan Metode

Advanced Encryption Standard Pada

Ponsel Berbasis Android. JSiI (Jurnal

Sistem Informasi), 4, 29-31.

https://doi.org/10.30656/jsii.v4i0.374

Sari, A. M., Lestari, R., Yani, D., Informasi, S., Informasi, F. T., Inggris, B., ...

Informatika, S. (2019). APLIKASI

PENGENALAN KEBUDAYAAN JAWA BERBASIS DESKTOP, 12(2).

Supendi, Y., Supriadi, I., \& Isto, A. A. W. (2019). Pemanfaatan Teknologi QR-Code Pada Sistem Presensi Mahasiswa Berbasis Mobile. Seminar Nasional ..., 550-558.

Retrieved from

http://publikasi.dinus.ac.id/index.php/semn astik/article/view/2912

Tampubolon, N. B., Isnanto, R. R., \& Sinuraya, E. W. (2015). Implementasi Dan Analisis Algoritma Advanced Encryption Standard ( Aes ) Pada Tiga Variasi Panjang Kunci Untuk Berkas Multimedia. Transient, 4(4).

Tan, R., Kartawihardja, D. S., \& Christian, I. (2017). Penerapan Teknologi RFID untuk Purwarupa Pencatatan Presensi Mahasiswa di Laboratorium Komputer, 3(2), 122-128.

Utami, Y. S., Wiendijarti, I., Pambudi, S. T., Sri Utami, Y., Wiendijarti, I., \& Tri Pambudi, S. (2019). Pengembangan Kurikulum Program Studi Hubungan Masyarakat Di Era Revolusi Industri 4.0. Jurnal JRPP, 2(1), 221-233. Retrieved from http://journal.universitaspahlawan.ac.id/ind ex.php/jrpp\%0Ahttps://core.ac.uk/downloa d/pdf/279462615.pdf 